\title{
Os Estudos Culturais e a influência da nova esquerda para uma nova teoria da cultura
}

\author{
Los estudios culturales y la influencia de la Nueva Izquierda para una \\ nueva teoría de la cultura
}

\author{
Cultural studies and the influence of the new left for a new theory of \\ culture
}

\author{
Rafaela de Souza Ribeiro ${ }^{1}$
}

\begin{abstract}
Resumo
O objetivo da presente exposição será apresentar as incursões que vimos realizando acerca da categoria cultura e sua relação com a totalidade social, a partir da tradição de estudos que concebe a cultura como constituinte do ser social e como modo de vida. Essa leitura é própria de autores da chamada nova esquerda, cujos principais expoentes são Raymond Willians, E.P Thompson, Richard Hoggart, entre outros. A iniciativa dos estudos na área se justificam pela importância e centralidade da categoria cultura no campo da teoria social e pela sua heterogeneidade e, portanto, necessidade de maior definição enquanto dimensão fundamental, principalmente como potencializadora de propostas de mudanças na realidade social a partir da superestrutura da sociedade contemporânea. A metodologia utilizada, foi uma revisão bibliografia que inclui uma incursão nos Estudos Culturais, desde o seu surgimento enquanto área específica de estudos e, também, na trajetória política de seus principais expoentes, o que nos revela pistas importantes para compreender suas diferentes fases de exposição e apropriação pela teoria social crítica e seu potencial de desvelamento e mudança da realidade social, como já sinalizado.
\end{abstract}

Palavras-chave: Cultura; Estudos Culturais; Nova Esquerda.

\section{Resumen}

El objetivo de esta exposición es presentar los avances que hemos tomado en la categoría de la cultura y su relación con la totalidad social, desde la tradición de los estudios que concibe la cultura como un constituyente del ser social y como una forma de vida. Esta lectura es propias personas que llaman Nueva Izquierda, cuyos principales exponentes son Raymond Willians, E.P Thompson, Richard Hoggart, entre otros. La iniciativa de los estudios en el área justificados por la importancia y la centralidad de la categoría de cultura en el campo de la teoría social y su heterogeneidad y por lo tanto necesitan una definición más precisa como una dimensión fundamental, sobre todo en la potenciación de las propuestas de cambio en la realidad social de la superestructura de la sociedad contemporánea. La metodología utilizada fue una revisión bibliográfica que incluye una incursión en los estudios culturales, desde su aparición como un campo específico de estudio y también en la carrera política de sus principales exponentes, que revela claves importantes para entender sus diferentes etapas de la exposición y la apropiación por la teoría social crítica y su potencial para el descubrimiento y cambiar la realidad social, como se ha señalado.

Palabras clave: Cultura; Estudios culturales; nueva izquierda.

\footnotetext{
${ }^{1}$ Mestre, Professora da Escola de Serviço Social da Universidade Federal do Estado do Rio de Janeiro (Unirio). Rio de Janeiro, Brasil. Email: ribeiro.rafaela@gmail.com. Trabalho apresentado no I Seminário Latino-americano de Estudos em Cultura-SEMLACult, Foz do Iguaçu/PR, Brasil, 2017.
} 


\begin{abstract}
The objetive of this exhibition will be to present the incursions we have been carrying out regarding the category of culture and its relationship with social totality, based on the tradition of studies that conceives culture as a constituent of the social being and as a way of life. This reading belongs to authors of the so-called New Left, whose main exponents are Raymond Williams, E.P Thompson, Richard Hoggart, among others. The initiative of the studies in this area are justified by the importance and centrality of the category culture in the field of social theory and by its heterogeneity and, therefore, the need for greater definition as a fundamental dimension, mainly as a potentiator of proposals for changes in social reality from the superstructure of contemporary society. The methodology used was a literature review that included an incursion into Cultural Studies, since its emergence as a specific area of studies and also in the political trajectory of its main exponents, which reveals important clues to understand its different phases of exposure And appropriation by critical social theory and its potential for unveiling and changing social reality, as already signaled.
\end{abstract}

Keywords: Culture; Culture Studies; New Left.

\title{
1. Introdução
}

O objetivo da presente exposição será apresentar as incursões que vimos realizando acerca da categoria cultura e sua relação com a totalidade social, a partir da tradição de estudos que concebe a cultura como constituinte do ser social e como modo de vida. Essa leitura é própria de autores da chamada nova esquerda, cujos principais expoentes são Raymond Willians, E.P Thompson, Richard Hoggart, entre outros. A iniciativa dos estudos na área se justifica pela importância e centralidade que a categoria cultura vem ganhando no campo da teoria social e, ao mesmo tempo, pela heterogeneidade de significados adquiridos. Tais justificativas apontam para a necessidade de maior definição e aprofundamento enquanto dimensão fundamental, principalmente como potencializadora de propostas de mudanças na realidade social a partir da superestrutura da sociedade contemporânea. A metodologia utilizada foi uma revisão bibliografia que inclui uma incursão nos Estudos Culturais, desde o seu surgimento enquanto área específica de estudos e, também, na trajetória política de seus principais expoentes, o que nos revela pistas importantes para compreender suas diferentes fases de exposição e apropriação pela teoria social crítica e seu potencial de desvelamento e mudança da realidade social, como já sinalizado.

Tomamos como ponto de partida os estudos iniciados pela chamada Nova Esquerda (New Left), que "foi um movimento que a partir de final dos anos 1950 reuniu diversos intelectuais britânicos em torno de novas formas de pensar e fazer política, interligados principalmente pelo viés dos Estudos Culturais" (CEVASCO, 2012, p 82). Seus principais membros estavam aglutinados em torno do Partido Comunista Britânico quando a crise de 1956 veio colocar um ponto final nesse alinhamento, em decorrência da quebra da União Soviéticas e do espraiamento das práticas Stalinistas. 
No entendimento de WILLIAMS E THOMPSON,

A cultura é entendida como força produtiva, como constituinte e constitutiva das relações de dominação de classe, e, concomitantemente, como elemento propulsor da transformação social. Nessa perspectiva, a revolução cultural torna-se parte constitutiva e constituinte da revolução social (MARTINS e NEVES, 2014, p.74).

Os teóricos seguem na direção dos aportes gramscianos ${ }^{2}$, cujas reflexões para pensar a realidade social, assim como em Marx, tomam como fio condutor a perspectiva teóricometodológica da totalidade, especialmente quando destaca a relação dialética entre economia e política, ou entre estrutura e superestrutura, objetividade, subjetividade. A obra dos autores referenciados aprofunda com solidez a temática e garante uma leitura crítica acerca da questão, com ênfase nas características de sociedades capitalistas ocidentais.

É possível dizer hoje que o marxismo conta com obras de peso sobre a questão da cultura, mas essa "quase tradição" não foi iniciada sem uma expressiva batalha de ideias e restrições. Acreditamos que situar a trajetória dos autores e seus modos de pensar e fazer política pode nos oferecer pistas relevantes para a compreensão das bases sócio históricas dos estudos culturais.

Diante do exposto apresentaremos aqui parte do estudo teórico realizado, elencando as trajetórias de Williams e Thompson, e suas contribuições para a formação da nova esquerda britânica. Na tentativa de realizar uma abordagem de cultura a partir da dimensão da totalidade e vinculada ao estudo da práxis social ${ }^{3}$, os referidos autores compõem um bloco relevante de teóricos que contribuíram para o avanço dos estudos culturais, observando os limites do marxismo ocidental em abordar o tema.

Em princípio, é importante destacar que é central na abordagem desses teóricos o lugar ocupado pela cultura, enquanto parte do processo produtivo e para a construção do ser social e das experiências compartilhadas comuns. Os autores partem da tradição Gramsciana e de seu marxismo humanista para reafirmar a importância da categoria cultura como chave importante de reflexão dos modos de vidas e do cotidiano das classes exploradas na sociedade capitalista.

\footnotetext{
${ }^{2}$ Com sua teoria política, Gramsci contribuiu enormemente para a construção de uma nova sociologia da cultura, sem abandonar os ideais propostos por Marx e Engels, principalmente de revolução socialista. Foi ele, influência ímpar para a construção dos Estudos Culturais da nova Esquerda.

${ }^{3}$ Enquanto categoria que descreve a relação direta entre ideia e ação. A noção de Práxis no marxismo não está restrita apenas a lógica de interpretação, mas sim de transformação da realidade. Não significa um retorno à consciência comum, do materialismo vulgar ou metafísico. Segundo Vasquez (2011), o fato histórico de o marxismo ter sido reduzido, e se reduzir ainda em certos casos, ao velho materialismo fecundo pela dialética, ou a um idealismo às avessas que faz dele uma metafísica materialista, pôde se produzir justamente por se ter esquecido ou deixado na penumbra o conceito de práxis como conceito central (não só interpretar, mas também transformar) (VASQUEZ, 2011, p.31).
} 
Embora Gramsci não teorize especificamente sobre a noção de cultura, suas obras no cárcere, demonstraram preocupação com tal temática, com os rumos da sociedade italiana no capitalismo e suas consequências para a formação da consciência de classe e da hegemonia do proletariado. Ambos tiveram suas trajetórias marcadas fortemente pela participação no Partido Comunista e pelo trabalho com educação de base de jovens e adultos operários, influenciando fortemente a organização social e política desses sujeitos na sociedade. Vale destacar a importância das noções de teoria e prática, onde consideramos que não cabe à teoria uma tentativa de se encaixar na prática, pelo contrário.

Na tradição crítico-dialética, partimos das experiências dos sujeitos, da práxis, das experiências compartilhadas para pensar a construção de uma nova realidade, não cabendo assim qualquer "aplicabilidade" de teorias explicativas em realidades analisadas. Como categorias distintas, mas articuladas e dinâmicas, consideramos que pensar a relação teoriaprática, numa perspectiva de totalidade, engloba a análise da realidade concreta, articulando a dinâmica das diferentes estruturas da sociedade. Assim, a prática traz experiências novas que rompem limites teóricos, daí o enriquecimento dinâmico da teoria.

A trajetória dos autores e suas contribuições teóricas apenas nos auxiliam na compreensão de experiências vivenciadas e nos possibilita refletir outras formas de sociabilidade, rompendo assim com práticas conservadoras que retiram dos sujeitos seu verdadeiro papel transformador. O lugar da teoria torna-se importante pois é em relação com a teoria que a práxis é compreendida. Entre teoria e prática deve haver unidade e não identidade, uma relação de autonomia é condição indispensável para que "a teoria sirva a prática, já que implica na exigência de que a teoria não se limite a ir a reboque da prática, e sim que, em maior ou menor grau, se antecipe a própria prática" (Vasquez, 2011, p.238).

\section{Williams e Thompson: A formação da nova esquerda britânica}

É na década de 1970, que Williams (1921-1998) teórico literário e professor de jovens e adultos, juntamente com Richard Hoggart, e outros teóricos dissidentes da crise instaurada no Partido Comunista Britânico, define um "novo campo de estudos", que ficou conhecido como Estudos Culturais ou materialismo cultural. A partir de uma perspectiva materialista da história e partindo das análises de Marx e Engels, os teóricos da nova esquerda, como ficaram conhecidos, perseguiam uma abordagem de cultura que pudesse estar mais afinada com as transformações ocorridas na Europa naquela conjuntura, principalmente na Inglaterra no final do século XVIII, que passava por transformações políticas e econômicas. 
Os primeiros representantes da nova esquerda, e aí podemos também incluir E.P. Thompson, criticavam fortemente o economicismo sem mediação ${ }^{4}$ de correntes mais conservadoras do marxismo, onde a determinação do econômico prevalecia nas análises do movimento histórico da sociedade. A crítica incidia diretamente sobre o materialismo economicista, marxismo idealista e materialismo mecânico (MATTOS, 2012).

Durante muito tempo os estudos culturais permaneceram na penumbra no campo da teoria social. As formas de apropriação mais vulgarizadas do marxismo reforçaram essa visão, quando separaram ainda mais a cultura da sociedade e da vida material. As principais críticas foram direcionadas ao idealismo Alemão e ao Estruturalismo Althusseriano. Conforme destaca Matos, (2012) o problema residiria no fato de no materialismo vulgar:

Em lugar de [se] fazer a história cultural material, que era a fase radical seguinte, ela [a cultura] tornou-se dependente, secundária, 'superestrutural': um campo de 'simples' ideias, crenças, artes, costume, determinado pela história material básica. O importante, no caso, não é apenas o elemento de redução; é a reprodução, de forma alterada, da separação entre 'cultura' e vida social material, que tem sido a tendência dominante do pensamento cultural idealista. Assim, as possibilidades totais do conceito de cultura como um processo social constitutivo, que cria 'modos de vida' específicos e diferentes, que poderiam ter sido aprofundados de forma notável pela ênfase no processo social material, foram por longo tempo irrealizadas, e com frequência substituídas na prática por um universalismo abstrato unilinear. Ao mesmo tempo, a significação do conceito alternativo de cultura, definindo a 'vida intelectual' e 'as artes', foi comprometida pela evidente redução a uma condição de superestrutura (WILLIAMS apud MATOS, 2012, p.25).

Raymond Williams nasceu no País de Gales, Reino Unido, no ano de 1921. Neto de agricultores e filho de um trabalhador ferroviário, Williams cresceu num ambiente no qual os ferroviários votavam no Partido Trabalhista Britânico e os pequenos fazendeiros votavam majoritariamente no Partido Liberal. Influenciado pelo pai socialista, teve suas primeiras aproximações aos escritos de Marx e Engels aos 14 anos, pensava apenas em ser um escritor e não tinha interesse em frequentar a universidade, mas por bom desempenho no colégio, Williams ganha uma bolsa e aos dezoito anos, vai para Cambridge fazer o curso de Letras em Inglês. Além dos estudos, se dedicou à militância estudantil, sendo membro do Partido Comunista e do Clube Universitário Socialista de Cambridge (CEVASCO, 2012). Com o seu ingresso no PCGB, se aproxima de um grupo de historiadores, dentre eles, Christopher Hill,

\footnotetext{
${ }^{4}$ Sem a captação do movimento e da estrutura ontológica das mediações através da razão, o método, que é dialético, se enrijece, perdendo, por conseguinte, a própria natureza dialética" (PONTES, 1995, p.81).
} 
Victor Kiernan, John Saville, Rodney Hilton, E,P.Thompson e Eric Hobsbawm, com o qual dividia a responsabilidade de escrever panfletos e artigos para o Partido Comunista.

Assim como Thompson, que também fazia parte do Partido Comunista à época, e se desligou, ambos atribuem em parte de suas obras o rompimento com os ideais do partido,

\begin{abstract}
que estavam de fato vinculados a ortodoxia que vinha da então União Soviética, quando as notícias das atrocidades cometidas pelo governo de Stalin vieram à tona e, sobretudo, quando da invasão soviética da Hungria, em $1956^{5}$. A partir de então, o alinhamento de alguns pensadores marxistas com o Partido Comunista foi rompido. Fazia-se, pois, necessário rever o pensamento marxista, de forma a pensar novas bases para a transformação social. Assim, alguns destes intelectuais, como Raymond Williams, Edward P. Thompson e Richard Hoggart, saíram do partido e formaram o que ficou conhecido como "Nova Esquerda". Este movimento posicionou-se ao mesmo tempo contra o elitismo e o conservadorismo da direita e contra o dogmatismo e o reducionismo da esquerda stalinista (TAVARES, 2008, P.8-9).
\end{abstract}

Preocupados com uma educação pública que divulgasse e defendesse os valores da cultura comum desses operários, em oposição aos valores gerais defendidos pela elite, eles se propuseram a repensar o conceito de cultura. Passaram, então, a valorizar a cultura dos "de baixo".

Tentando reformular o conceito de cultura sem, no entanto, abandonar os princípios de Marx que os orientavam, eles passaram a estudar e a traduzir, além de publicar, vários pensadores marxistas europeus na revista The New Reasoner como, por exemplo, a obra do italiano Antonio Gramsci. O objetivo central era analisar o pensamento teórico marxista, tentando rever a questão do economicismo, de forma a incluir neste pensamento a preocupação com a questão da cultura.

Para Williams (2011) configura-se nesse sentido, uma dificuldade, onde - a compatibilidade de uma especialização crescente com uma cultura genuinamente comum - só se resolverá num contexto de comunidade das condições materiais da sociedade e através do processo democrático em sua plenitude (WILLIAMS, 2011, p.341).

\footnotetext{
${ }^{5}$ Até 1956, a esquerda marxista se aglutinava em torno do Partido Comunista da Grâ-Bretanha (CPGB). Embora nunca tenha sido um partido de massas como na Itália e na França, o Partido Comunista Britânico, fundado em 1920, desempenhou um papel importante no cenário político e cultural. Nos 1930, organizou o popular Front, uma reunião de forças sociais progressistas contra o fascismo, que teve como um de seus momentos altos o apoio às forças republicanas na Guerra Civil espanhola (1936-1939). O PCGB era também um partido de intelectuais proeminentes nas universidades tradicionais britânicas, Oxford e Cambridge, e na London School of Economics. Era parte integrante de uma florescente cultura de esquerda nos anos de 1930, os anos da Grande Depressão e da ascenção do fascismo, pela primeira vez na história dominava a vida intelectual inglesa (CEVASCO, 2012, p.81).
} 
É importante destacar nesse sentido, que o conceito de cultura que nos refirimos, não desconsidera o lugar da política para uma leitura mais completa da realidade. Não se tem aqui o objetivo de exaltar essa noção com um propósito pós-modernista onde tudo abrange e pouco tem a dizer sobre política, economia e cultura.

Thompson (1924-1993) historiador e militante político, para além dos muros da academia, teve sua produção teórica visceralmente articulada à sua trajetória política, quer como membro do Grupo de Historiadores do Partido Comunista da Grã-Bretanha, quer como militante da Campanha pelo Desarmamento Nuclear (CND) quer como editor do jornal The New Reasoner, verdadeira origem do movimento político que ficou conhecido como Nova Esquerda. Sem falar dos seus 17 anos de militância como professor de jovens e adultos; e também de sua participação na criação da Associação Educacional de Trabalhadores, com objetivo de socializar e defender os valores da cultura operária, em contraposição aos valores da burguesia (MATTOS, 2012).

É a partir dessa trajetória comum, que Thompson e Williams apresentam propostas similares, no que se refere à abordagem dos Estudos Culturais. A vivência com educação de homens simples, de jovens e adultos e sua inserção da militância comunista, facilitou a compreensão de que algo a mais deveria ser melhor aproveitado na trajetória dos estudos marxistas que predominavam na época, com o então idealismo e com o estruturalismo, que propunham outras saídas para os problemas do homem e da sociedade.

Para Thompson, "economia" e "cultura" não representam momentos estanques da "base" e "superestrutura"; a cultura não está á reboque dos fenômenos econômicos, mas se constitui na mesma rede de relações (THOMPSON, 2001). Nesse sentido, a classe social deve ser analisada tanto como formação econômica quanto cultural, tal qual ele assinala em Algumas observações sobre classe e consciência de classe. Assim como observa em uma de suas principais obras, A formação da classe operária Inglesa, "a classe é um fenômeno histórico, resultado de relações entre os homens reais em contextos reais" (THOMPSON, 2010, p.110). A noção de experiência é central para tal apreensão, uma vez que para o autor,

quando falamos de uma classe, estamos pensando em um corpo de pessoas, definido sem grande precisão, compartilhando a mesma categoria de interesses, experiências sociais, tradição e sistemas de valores, que tem disposição para se comportar como classe, para definir, a si próprio em suas ações e em sua consciência em relação a outros grupos de pessoas, em termos classistas [...] É fruto de experiências comuns que podem levar à formação de uma determinada identidade, que por sua vez, se coloca contra a identidade de outros homens em função de interesses materiais e culturais que são opostos (THOMPSON, 2010, p. 10). 
Mattos (2007) destaca que Thompson manifesta como princípio de análise a conexão entre as relações de produção e a consciência de classe, através da mediação da experiência, o autor reforça seu estudo no polo da consciência, bem como seus condicionantes e constituintes em termos culturais e de valores morais. Nesse sentido, para o autor, sua obra procura resgatar a questão da determinação, defendendo que "há uma simultaneidade da manifestação de relações produtivas particulares em todos os sistemas e áreas da vida social" (MATTOS, 2007, p.46).

Em uma passagem de As peculiaridades dos Ingleses e outros artigos, Thompson reforça a falência dos conceitos base e superestrutura, e esclarece:

\begin{abstract}
a boa sociedade pode ser simplesmente criada (tal como na teoria stalinista) a partir da construção de uma base industrial pesada; isso dado, uma superestrutura cultural irá, de algum modo, construir-se sozinha. Numa variante mais recente, a althusseriana, com ênfase na "autonomia relativa" e na "determinação em última instância", os problemas do materialismo histórico e cultural são deixados sem solução, assim como embaralhados e elididos (THOMPSON, 2001, p.256).
\end{abstract}

Na mesma direção, Williams sinaliza a importância de resgatar esses conceitos a fim de realizar uma análise mais cuidadosa, onde a partir do próprio Marx, dando ênfase nas atividades produtivas em relações estruturais específicas (que constitui o alicerce de todas as outras atividades), refere que essa base não é estática, e pode sofrer constantes variações na dinâmica dessas forças. Logo, é um processo e não um estado. Resgata três pontos importantes:

1) A "determinação"- para a fixação de limites e o exercício de pressões, afastando-a de um conteúdo previsto, prefigurado e controlado.

2) A "superestrutura"- em direção a uma gama de práticas culturais relacionadas, afastando-a de um conteúdo refletido, reproduzido ou especificamente dependente;

3) A "base"- que é compreendida no marxismo enquanto forças produtivasafastando-a da noção de uma abstração econômica e tecnológica fixa e aproximando-a das atividades específicas de homens em relações sociais $e$ econômicas reais, atividades que contém contradições e variações fundamentais e, portanto, encontram-se sempre num estado de processo dinâmico (WILLIAMS, 2011a, p.47).

No marxismo vulgar esses conceitos foram empregados de forma a desconsiderar a dinâmica das classes subalternas, engessando-a, isso rebate no campo da cultura, uma vez que a enquadra na superestrutura, sempre determinada pela base. Isso implica de certa forma uma necessidade de avançar para o estudo de outros conceitos subjacentes a esse, como é o caso da 
totalidade, e da hegemonia ${ }^{6}$, que de certo, não daríamos conta neste texto. Porém, vale destacar a crença de Williams, que podemos usar corretamente a noção de totalidade apenas quando combinada com a de hegemonia, por que cada sociedade tem uma organização e uma cultura específica.

\begin{abstract}
O que eu gostaria agora de afirmar ter alcançado, mas necessariamente por essa via, é uma teoria de cultura como um processo (social e material) produtivo e de práticas específicas, e das "artes" como usos sociais dos meios materiais de produção (desde a linguagem como "consciência prática" material até as tecnologias específicas da escrita e das formas de escrita, por meio de sistemas mecânicos e eletrônicos de comunicação [...] Ainda insisto no fato de que isso não é uma loja de opções teóricas, mas é, ou pode tornar-se, uma teoria das variações históricas do processo cultural, que então se conecta necessariamente (tem que estar conectado) a uma teoria social, histórica e política mais geral (WILLIAMS, 2011a, P.332).
\end{abstract}

Para os membros da New Left, cultura não era uma esfera da consciência separada do ser social, mas designava um processo central e uma arena de luta social e política. Partindo então da assertiva de Marx, onde "o ser social determina a consciência", a conclusão mais comum que vem dessa proposição é que seria preciso mudar o ser social para atingir uma mudança de consciência.

$\mathrm{O}$ conceito de cultura deve ser investigado pelos diferentes significados que incorporou até se tornar um campo de estudo autônomo no século XX, sem deixar de retomar, para isso, alguns conceitos chaves (que estão relacionados às tentativas de explicação para tais mudanças) com o objetivo de resgatar o lugar do popular e das massas nesse processo.

Assim, para os estudos contemporâneos, trabalhar na chave da cultura, significa realizar escolhas teóricas capazes de romper com visões românticas e elitistas, assim como apontar para uma renovação de conceitos a fim de recompor a ideia de cultura sem perder de vista as contradições que lhes são inerentes. Serão muitas as tentativas de retorno aos velhos conceitos, que se reatualizam nesse complexo, como forma de garantir poder e subjugar o que não se adéqua à ideologia da cultura dominante.

Referências:

CEVASCO, Maria Elisa. Dez lições sobre estudos culturais. SP: Boitempo Editorial, 2012.

\footnotetext{
${ }^{6}$ Aqui o conceito de hegemonia tem influencia dos estudos de Gramsci, onde "a hegemonia pressupõe algo verdadeiramente total, não apenas secundário ou superestrutural, como no sentido fraco de ideologia, mas que é vivido em tal profundidade, que satura a sociedade a tal ponto e que, constitui mesmo a substância e o limite do senso comum para muitas pessoas sob sua influência, de maneira que corresponde à realidade da experiência social muito mais nitidamente do que qualquer noção derivada da fórmula de base e superestrutura" (Williams, 2011a, p.51).
} 
MARTINS, A. M. S. e NEVES, L.M.W. Materialismo histórico, cultura e educação: Gramsci, Thompson e Wwilliams. Revista HISTEDBR On-line, Campinas, nº 51, p. 341-359, jun2013 - ISSN: 1676-258 341. Disponível em: https://periodicos.sbu.unicamp.br/ojs/index.php/histedbr/article/view/8640281/7840 (Artigo em Periódico Digital). Acesso em 10/06/2017.

MATTOS, M. B. Classes sociais e luta de classes: a atualidade de um debate conceitual. In Revista Em Pauta- teoria social e realidade contemporânea, n. 20, Rio de Janeiro, Ed.UERJ, 2007. (Artigo em periódico físico)

MATTOS, M. B. O marxismo inglês da 'Nova Esquerda' e o debate materialista sobre cultura e alienação, 2012. Disponível em: http://www.herramienta.com.ar/coloquios-yseminarios/o-marxismo-ingles-da-nova-esquerda-e-o-debate-materialista-sobre-cultura-e-al. (Artigo em Periódico Digital). Acesso em 10/06/2017.

PONTES, Reinaldo Nobre. Mediação e Serviço Social. São Paulo: Cortez, 1995.

TAVARES, H.M. Raymond Williams: pensador da cultura. Revista Ágora, Vitória, n.8, 2008, $\quad$ p.1 $27 . \quad$ Disponível em: http://www.periodicos.ufes.br/agora/article/viewFile/1927/1439 (Artigo em Periódico Digital). Acesso em 07/06/2015.

THOMPSON, E.P. A peculiaridade dos ingleses e outros artigos. Negro, A.L. e Silva, S. (orgs); Campinas: Unicamp, 2001, p. 269-281.

THOMPSON, E.P. A Formação da classe operária inglesa. Rio de Janeiro : Paz e Terra, 2010. V.1.(5 $\left.5^{\mathrm{E} d}\right)$.

THOMPSON, E.P. Costumes em comum. Estudos sobre a cultura popular tradicional. São Paulo Companhia da Letras, 1998.

THOMPSON, E.P. Os românticos. A Inglaterra na era revolucionária. Rio de Janeiro, Civilização Brasileira, 2002. 
VASQUEZ. A. S. Filosofia da Práxis. 2ªed. CLACSO: SP: Expressão Popular, 2011.

WILLIAMS, R. Marxismo e Literatura, Rio de Janeiro, Zahar, 1979.

WILLIAMS, R. Cultura e materialismo. São Paulo, Ed Unesp, 2011a.

WILLIAMS, R. Cultura. SP: Ed. Paz e Terra,1992.

WILLIAMS, R. Cultura e Sociedade. Rio de Janeiro: Zahar, 1992.WILLIAMS, R. Cultura. São Paul, Paz e Terra, 2011. 